\title{
Metis grega e simulacro em $O$ Programa de Televisão (1990), de Michel Vinaver
}

\author{
Catarina Sant'Anna
}

Análise dos jogos lingüísticos e da metalinguagem implicados no tema da mentira e da manipulação na comédia O Programa de Televisão/L'Emission de télévision de Michel Vinaver (1927), através da noção grega de metis (a inteligência astuta na Grécia mítica) e das noções de simulacro e simulação de Jean Baudrillard.

Palavras-chave: metis - Vinaver - metalinguagem - simulacro e simulação

\section{Abstract}

Analyse of langage games, and metalangage, which built the theme of lie and the manipulation of the comedy L'Emission de Télévision/The Television Program (1990) by Michel Vinaver (1927), through the Greg notion of "métis" (the smart intelligence in the mythical Grece) and the notions of pretense and simulation by Jean Baudrillard.

Keywords: métis - Vinaver - metalinguagem - pretense and simulation

\footnotetext{
1 Conferência apresentada originalmente em francês nas Journées d'Etudes sur la Manipulation dirigidas por Jean-Charles Margotton, na Universidade Lumière Lyon 2, França, em 30/06/2007.

2 Professora Dra Associada no PPGAC-UFBA, ex-profa do Dep. de Artes Cênicas, da Imagem e da Tela, do Instituto de Letras, Ciências da Linguagem e Arte, da Universidade Lumière Lyon 2 (2004 a 2006), doutora e pós-doutora pela USP (1989 e 1991), publicou traduções e estudos sobre o teatro de Michel Vinaver (EDUSP, 2007), tem prontas a publicar mais traduções com estudos desse autor, feitos em pós-doutorado no Institut d'Etudes Théâtrales, da Universidade Sorbonne Nouvelle Paris-3 e IMEC-Abadia de Ardennes (2010-2011). Publicou ainda Para Ler Gaston Bachelard- ciência e arte (Edufba, 2010) e Metalinguagem e teatro -a dramaturgia de Jorge Andrade (Perspectiva, 2012).
} 
O tema da mentira na comédia O Programa de televisão (1990) de Michel Vinaver revela-se complexo, pois integra o fenômeno mais geral da manipulação, que é indissociável de outros elementos tais como sedução, disfarce e condicionamento - ou descondicionamento - de um comportamento. Nesse sentido, o texto dramático constitui um domínio privilegiado de análise, porque no teatro falar é agir - e agir justamente sobre outrem, como atesta a função conativa da linguagem (Jakobson), geralmente dominante no discurso dos personagens teatrais. Acresce que o teatro é igualmente theatron, "lugar de onde se vê" e um lugar de fantasmas (Pavis) ou de sombras coletivas (Duvignaud), onde a sociedade se vê refletida e onde podem ressoar mitos antigos. Quais seriam, então, as estratégias discursivas e dramatúrgicas postas em cena e quais seriam seus efeitos poéticos e ideológicos os mais notáveis no tratamento da televisão pelo teatro nesta peça de 1990 ?

\section{Da metis à manipulação: implicações míticas e sociais}

Michel Vinaver diz não pretender "denunciar" o sistema, mas tão somente "desmontá-lo" por meio de seu teatro ${ }^{3}$ - um "teatro da palavra" onde o lugar ocupado pelas relações entre personagens por meio de diálogos plenos de ardis ganha importância fundamental. A peça O Programa de Televisão, por exemplo, é prenhe de manobras verbais de todo tipo, que visam a tecer uma espécie de teia de aranha onde se enredam todos os personagens. Trata-se aqui de uma inteligência tática dentro de um quadro de competição generalizada pela conquista de espaço, quando não há espaço para todo mundo: trata-se do universo do trabalho para os que já ultrapassaram

\footnotetext{
3 Peças de Vinaver: Os Coreanos (1956), Coros para Antígona (1956), Les Huissiers/ Os Ajudantes de ordens (1958), Iphigénie Hôtel (1960), Par-dessous bord/ Além dos limites (1972), Pedido de emprego (1972), Dissidente (1978), Nina, é outra coisa (1978), Les travaux et les jours/ Os Trabalhos e os dias (1979), Á la renverse/ Na Contramão (1980), L'Ordinaire/ O Corriqueiro (1982), Les voisins I Os Vizinhos (1986), Portrait d'une Femme/ Retrato de uma Mulher (1986), O Programa de Televisão (1990), Le Dernier sursautl O Último susto (1990), King (1998), L'Objecteur/ O Objetor de consciência (2001), 11 Septembre 2001/ 11 September 2001 (2002), Les Troyennes/ As Troianas (2003).
}

a idade dos cinqüenta anos; e do mundo do jornalismo escrito ou televisivo em busca de novidades; ou da ascensão dentro da carreira judiciária; ou da concorrência no comércio, na indústria, nas relações amorosas ou familiares. Tudo isto repercutindo no tecido social que se vê finalmente ameaçado de desagregação e de caos no plano de suas instituições.

Antes de tudo, porém, é importante observar conceitualmente que os domínios da astúcia e da manipulação (bem como o da simulação) ainda que se cruzem na prática social, não devem, por definição, confundir-se. Para começar, é no plano mítico que se deve procurar referências para um gênero de inteligência astuciosa e prática que os antigos gregos denominavam metis (Detienne, 2004, p.10-13, 25-28, 48-55, 271298) e cuja presença na sociedade encontrase atestada por documentos pertencentes aos domínios da caça e da pesca, da tecelagem e outras atividades artesanais, bem como na área da navegação, da guerra naval, na política e na medicina, na epopéia, na retórica e na filosofia. Trata-se de vencer pela astúcia um adversário mais poderoso, seja este um animal, um homem, uma força natural, uma doença, um discurso. A metis constituía uma operação intelectual, uma atitude do espírito, uma forma pensada que se utilizaria de manobras, de estratagemas e de habilidades bem precisas como "o faro, a sagacidade, a previsão, a flexibilidade de espírito, o fingimento, o desembaraço, a atenção vigilante, o senso de oportunidade, habilidades diversas, uma experiência longamente conquistada" (Detienne, 2004, p. 10); como também a duplicidade, a ambigüidade, a capacidade de se mostrar diferente do que se é realmente, de preparar emboscadas e não deixar nunca escapar boas ocasiões, momentos propícios e instantâneos (Kairós) para agir e vencer.

Esse tipo de comportamento astucioso tem lugar em realidades mutantes, fugazes, desencorajadoras e ambíguas, múltiplas e ondulantes, polimorfas e polivalentes, imprevisíveis, plenas de indeterminação e onde pode jogar o acaso. Em suma, trata-se 
do enfrentamento de situações em que forças hostis são por demais poderosas para serem atacadas diretamente. Daí a necessidade de nos adaptarmos a tais realidades e nos mostrarmos mais flexíveis, mais rápidos, mais móveis, mais ardilosos, polimorfos e inatingíveis que as próprias situações, e agir de viés para podermos nos sair bem. Trata-se de confrontar um mundo instável em que a astúcia pode vencer a força e até o mérito verdadeiro.

Ora, esse tipo de comportamento produziu um tipo de personagem popular, enganador e dotado de mil expedientes, nas muitas diferentes culturas e literaturas, como o herói picaresco ibérico, ou o trickster anglo-saxônico, cujas origens remontam a Homero a aos mitos antigos, como os que, por exemplo, têm Hermes como protagonista. Mas é Zeus (Detienne, 2004, p. 292-293) que, engolindo sua primeira esposa, a deusa Metis justamente, tornou-se poderoso o bastante para conseguir controlar as desordens entre os deuses e poder instalar uma ordem imutável graças a uma distribuição equilibrada e limitada de saberes e de poderes entre todos, a fim de assegurar a própria soberania sem maiores incidentes de importância. Todavia essa vertente curiosa do pensamento grego foi negligenciada pelos filósofos do VI século AC e, mais tarde, também pelos historiadores do pensamento antigo, e isto foi feito em proveito do conhecimento racional e da lógica identitária, pautados pelo verdadeiro, o mensurável e o exato (Detienne, 2004, p. 10-12; 56; 295-298; 305-306), fenômeno este que marcou o pensamento ocidental.

Mantendo-se valorizada no domínio da estratégia militar, a metis vê se produzir a partir do século XVI expressões para a astúcia da guerra, como "manigances" (tramóias) e "manoeuvres" (manobras), e que progressivamente passam a conotar impostura, mentira, ilusão, até o surgimento de um novo uso para o vocábulo "manipulação", que no século XVIII extrapola o domínio da química e passa a conotar a "manipulação de uma pessoa" - e isto justamente nesse século em que surgiu a ins- tituição do contrato social que objetivava por um fim ao uso das violências na resolução dos conflitos, para instaurar uma estabilidade social que favoreceria o comércio e a propriedade, quando "o compromisso no diálogo substitui a opressão pela força" (D'Almeida, 2005, p. 26). Um sistema jurídico estabelece-se então para garantir que se cumpram os compromissos, pela submissão a leis específicas e procedimentos precisos de julgamento. Em conseqüência, a Verdade se desloca, em nome da objetividade e da justiça, "da questão das essências à [questão] dos comportamentos" (D'Almeida, 2005, p. 26), uma vez que é preciso crer em uma "correspondência direta entre atos visíveis e pensamentos imperceptíveis". Neste contexto, a astúcia perde teoricamente sua razão de ser, em nome da transparência e da cessação dos abusos. Mas o homem, entretanto, tornado vítima da usurpação pelo sistema econômico que o coisifica, se vê instrumentalizado e manipulado no seio de uma sociedade massificada que o faz interiorizar normas e condicionamentos alienantes. Todo esse excesso de manipulação pelo sistema acaba por produzir uma desrealização da realidade e, conseqüentemente, por criar simulacros de real, como bem postulou Jean Baudrillard, quando então as questões da mentira e da verdade já não têm mais sentido, pois perderam sua razão de ser.

\section{Pressa, agon, metis e manipulação na selva vinaveriana.}

Em O Programa de Televisão, tempo é literalmente dinheiro. É preciso agir e reagir rápido, sabendo capturar o momento propício (Kairós). Os meios de comunicação parecem impor sua urgência enquanto usinas de produção de informação para o consumo bulímico da sociedade: uma jornalista free-lancer, Jacky, faz compreender ao jovem juiz de instrução, Phélypeaux, que o caso do assassinato de um ex-desempregado de mais de cinqüenta anos se arrasta sem solução; as jornalistas de televisão, Adèle e Beatriz, diante da perda de audiência atestada por um instituto de son- 
dagem, são obrigadas a produzir um programa de televisão sem falhas sobre a felicidade de se sair do estado de desemprego; e dois ex-desempregados de longa data e idosos com mais de cinqüenta anos disputam a sorte de aparecer na televisão, sendo ambos incentivados por suas respectivas esposas; policiais se lançam numa única pista para resolver o mistério do assassinato estampado nas manchetes; uma grande loja, em conivência com um canal de televisão, e por interesse comercial, emprega um desempregado de longa data e de mais de cinqüenta anos; um jovem do tipo vinaveriano "dissidente do sistema", pintor e marginal, encarna o estraga-prazeres, mas acaba sendo devorado pela engrenagem do sistema. Na corrida contra o tempo, entra em jogo o agon - uma competição generalizada- e toda espécie de expedientes para vencer em detrimento de outrem, num reino de trapaças.

Enquanto os personagens são dotados de qualidades animais para caça e pesca, os animais surgem humanizados, velhos, doentes, dependentes e mais sensíveis que os humanos: é o caso do gato de Jackie, que ela prefere à própria família; ou a cadela cega, Azur, pertencente aos Blache, a única a perceber a morte de seu dono. $\mathrm{O}$ poder de mirar sua presa e de se lançar para abocanhá-la caracteriza as três jornalistas como aves de rapina, como nessa passagem de um duo cínico: "Adèle. Um pouco de sorte um pouco de faro/ Béatrice. Antenas/ Adèle. Necessário saber planar/ Béatrice. $\mathrm{O}$ acaso / Adèle. A arte de utilizá-lo/ Béatrice. Manejar o vento/ Adèle. Amar as pessoas/ Béatrice. É importante/ Adèle. Do alto do céu/ Béatrice. As asas abertas/ Adèle. A providência ajudando/ Béatrice. Mergulhar/ Sra.Delile. Como os anjos?/ Risos./ Adèle. É sua profissão amar. Silêncio" (p. 12). Certamente são elas os "pássaros que faziam um barulho ensurdecedor" em torno do juiz, nos sonhos premonitórios da escrevente Srta Belot. Como se vangloria Adèle: "A gente fareja, aspira/ Detecta”, "Você não ía largar o osso/ Eu me lancei". Quanto ao personagem Jacky, ela "é mais rápida que o vento", ela "tem nariz", ela "fareja", é "tenaz", capta a hora certa: "o destino me acenou", "preciso acionar o destino de novo"; "preciso furar uma brecha". Já o ex-desempregado Sr. Blache identifica-as como pertencente à "equipe de batedores de caça" de Vicent Bonnemalle, o diretor do programa de televisão em questão e cujo nome indica um personagem polimetis dos mais poderosos, furta-cor, bom e mau ao mesmo tempo. Os policiais, segundo o juiz, "se engalfinham" numa pista "como uma horda de javalis", enquanto que ele próprio, como juiz, se joga sobre o desempregado Delile e sobre a viúva Blache com uma rede envolvente de perguntas-armadilha.

Quanto aos termos usados, a voracidade do juiz e das jornalistas fá-los compartilhar o adjetivo "suculento" para avaliar suas presas e, tal como Jacky, "gatinha esfaimada", eles necessitam de "algo para por entre os dentes", evidenciando uma disposição para canibalizar o outro. Não é por acaso que uma das pinturas de Paul apresenta um homem de três cabeças, asas de morcego e bocas onde "ele mói com os dentes". Quanto às vítimas, o léxico não é menos expressivo: segundo Jacky, o Sr. Delile "foi fisgado de harpão por uma cadeia de televisão" e ela própria "pegou um passarinho ferido" (o jovem Paul). Para o juiz, o Sr. Delile é um "pássaro cativante" que se debate de "asas abertas", "se debate como um lobo na armadilha", sendo um negócio realmente "suculento" que ele "agita em todas as direções" e sente "que está prestes a jorrar"; enquanto que Delile desconfia: "Talvez seja a sua técnica de tentar me desacorçoar". Aliás, Delile tem sempre a impressão paranóica, mas bem compreensível, de ser "um animal" que tem que se esconder do olhar de outrem.

Em síntese, todos os personagens se repreendem uns aos outros por terem "trapaceado, mentido, traído", e usam a expressão "dever tudo a alguém" nessas situações. A manipulação ocorre sob a forma de contratos e de alianças ilícitas ou fora de normas. O desempregado Blache propõe trabalhar sem salário, para reerguer a pequena indústria onde Delile ocupa uma 
função de direção, e acaba por tomar seu lugar. Já a jornalista Adele trama às costas de Beatriz, para se fazer indispensável aos olhos do patrão Bonnemalle, pois haverá corte nos efetivos. O próprio Delile tinha progredido dentro da indústria porque era "um fuçador inventivo": "Eu metia o nariz em tudo e levava boas idéias para fazer cair o preço de revenda/ Me nomearam chefe do serviço e depois diretor". Jacky exige do juiz um acordo "toma lá dá cá": a promessa de exclusividade para noticiar a sentença na imprensa, em troca da revelação de pistas do crime. Mas a televisão exige o mesmo, insinuando que destruiria o juiz (Bonnemalle evoca ser amigo do ministro da justiça e evoca também a opinião pública - milhões de telespectadores sob seus caprichos). Enquanto que Delile desconfia de seu novo patrão e de sua rede hierárquica de dimensões continentais, que lhe tornaria fácil descumprir um contrato de trabalho. Bonnemalle por sua vez toma decisões de maneira bem obscura na direção do programa de televisão. E até as relações amorosas entre Paul et Jacky nascem sob o signo de armadilhas e desconfiança recíproca, quando manipulação joga com sedução, mentira, disfarces e tentativas de condicionamento do comportamento do outro para dobrá-lo a interesses pessoais.

\section{Manipulação dramatúrgica: código vinaveriano versus código televisivo}

Michel Vinaver põe no centro da peça uma longa discussão sobre dramaturgia, na qual está na berlinda o pretenso gosto do espectador e os meios a mobilizar para satisfazê-lo, assim como discussões ou observações isoladas sobre a performance pessoal para alguém se tornar convincente na vida social. Estaria em jogo o tropo barroco do "theatrum mundi", se não se tratasse ali de um processo de simulação de tal forma maximizado do real, que faz a dicotomia aparência/essência, ou mentira/verdade perder o sentido e a razão de ser. O disfarce é largamente praticado, pois é preciso simular ser o que não se é absolutamente, ou não se é o bastante para poder convencer outrem a agir à revelia de seus próprios interesses. A produção de imagens pessoais ou institucionais está em jogo todo o tempo, seja para mascarar uma realidade indesejável ou inconsistente, seja para tornar uma realidade ainda mais credível através de um superávit de real: a escrevente Srta Belot diz a propósito da viúva Blache: "Todas sempre se crêem obrigadas a encenar seu pesar mesmo quando este é real". A jornalista Beatriz pressiona e condiciona o Sr. Delile a crer realmente na virada de sua vida, pois toda a encenação elaborada pelo programa pode não se revelar suficientemente convincente para a massa dos telespectadores: "Para o programa é absolutamente necessário que todo mundo veja que o senhor acredita nisto". Ironicamente, é citado um programa que abordava "o retorno da fé", mas que apresentara cenas do suicídio coletivo dos membros de uma seita religiosa na Guiana. Já Blache, o outro desempregado, de temperamento otimista e fã de televisão, ao ser entrevistado por Adèle sobre como havia saído do desemprego, já leva bem amarrada sua história de soerguimento pela fé e evoca o mito literário do naufragado Robinson Crusoé. A ironia vinaveriana faz com que este personagem, afinal escolhido como o herói do programa, apareça morto misteriosamente às vésperas da gravação e que seja posto em seu lugar justamente o pessimista e desconfiado Delile, o qual será condicionado a aparentar um estado visualmente credível de felicidade, por meio da via da simulação: "Confie na dinâmica do programa/ Se foi escolhido para encarnar a esperança/ Alguma coisa vai se produzir no senhor, Sr. Delile".

Uma importante premissa do código vinaveriano, e tomada emprestada a Goethe, afirma que não se deve procurar nada sob as superfícies porque são elas justamente o segredo. Daí a inexistência do não-dito, posto que, segundo Vinaver, tudo é dito e não é necessário cavar uma profundidade, nem mesmo psicológica, uma vez que não há nada nem antes, nem após, mas tão somente o presente imedia- 
to, urgente, dos personagens. Tal imagem sem avesso, sem referente, que tem valor em si mesma, poderia ela remeter ao domínio do puro simulacro, como postulado por Baudrillard?

Quais são então os instrumentos dramatúrgicos em jogo por Vinaver? Para visar quais efeitos? Como um bom mestre tecelão, o autor empresta ao seu texto o aspecto de uma estrutura desmantelada, a fim de obter um certo efeito de fragmentação do real, tal como ocorre no quotidiano e tal como se produz na televisão, Aliás, já a primeira didascália de $O$ Programa de Televisão recomenda uma encenação num só movimento: “Um pouco como se o espectador, munido de um controle remoto, zapeasse face ao espaço do jogo". Segue-se o arranjo das cenas, ou melhor, dos 20 "pedaços" (morceax), que embaralham presente e passado até o pedaço $\mathrm{n}^{\mathrm{O}} 14$, após o qual os acontecimentos se encadeiam, ou melhor, se justapõem num tempo presente até o final. São flashs da vida quotidiana, da realidade mutante capturada na fulgurância de seus instantes, que surgem conectados, mas não subordinados - o que desautoriza os termos tradicionais "cenas" e "atos". Esta fragmentação se repete no plano dos diálogos escritos sem pontuação (salvo o ponto de interrogação) e desprovidos de didascálias externas: as falas se cruzam, se dispersam, ou ficam sem respostas, e misturam de repente referentes disparatados, ou exibem um laconismo espesso feito de informação e de suspense, e se estancam no ar, reaparecendo mais tarde misturadas a outros dados. Tudo parece amarrado para impedir o encadeamento nítido de causas e de conseqüências da dramaturgia convencional - as "peças-máquinas", no jargão de Vinaver- e evitar também um ponto de vista globalizador ou a redução do texto a uma moral ou mensagem hegemônica, já que todos os pontos de vista são válidos, sem hierarquizações nem julgamento, nessa "peça-paisagem" (termo do autor), em que tudo vem exposto de forma a evitar classificações maniqueístas opondo culpados a inocentes.
Desse modo, a representação teatral em O Programa de Televisão tenta resgatar a complexidade de um certo real ao qual não podem ser aplicadas as noções de verdadeiro e de falso, uma vez que este real teria se tornado ele próprio pura imagem, ao final de um excesso de manipulações operado notadamente pela mídia. Disso resulta um "hiper-real" (Baudrillard) fabricado para substituir um mundo vazio de todo sentido e de toda autenticidade.

\section{A dissolução do real: um quadro de indeterminação generalizada}

Duas diferentes visões de dramaturgia televisiva opõem as duas jornalistas, Adèle e Béatrice: uma requer a estruturação do programa em polos nítidos - sombra e luz, bem e mal, felicidade e infelicidade-, a outra defende um efeito dégradé entre tais polos. Os diálogos nos informam que a nova tendência das cadeias televisivas recai justamente sobre um quadro nítido de valores bem opostos, o que nos parece sintomático de um movimento de ação sobre um real que já não existe, justamente para reabilitá-lo por meio de um acréscimo de real. Dito de outra forma, trata-se de fazer crer, através da telinha das tevês nos lares, que ainda existe real, donde o esforço bastante minucioso de simulação empreendido pelo programa, cujas técnicas objetivam antes fabricar o real, do que realmente "representá-lo". O resultado final, apesar de tudo, é entrevisto pela Sra Delile toda deslumbrada: "Não é verdade é um conto de fadas". Ora, o iconoclasmo do código vinaveriano de representação vai no sentido inverso desta idolatria das imagens, justamente para lhes demonstrar o oco.

Para sintetizar, a dissolução do real implica uma desconstrução dos dramas do real vivido, a depreensão de seus signos e o rearranjamento desses na construção de um outro real já expurgado do perigo de toda instabilidade e de toda espontaneidade própria à verdadeira dinâmica social. Ora, uma tal desconstrução só pode ocorrer por meio de uma reificação do homem e de seus valores, para que o processo de 
manipulação aconteça de modo eficaz. Assim, a notícia súbita da morte de Blache, escolhido para ser o herói do programa, não produz mais que gargalhadas por parte das jornalistas em jogo: "Basta dizer a Vincent que a máquina continua a andar temse um pneu de recarga". Alias, a Sra Blache já tinha mencionado a desconstrução do marido: "Eu o via dissolver-se sob minhas vistas eu nada podia fazer". Ou comentando o olhar de outrem sobre eles como sendo lançado sobre "alguém que derrete". E cabe a esta Sra Delile, por sua vez, pedir ao seu marido que ligue "a tevê para o boletim das 20 horas", para que possam ser informados sobre a morte do amigo (e vizinho!!) Sr. Blache. Este, tal como Delile finalmente, não passava de um objeto de dissecação com vistas a suas possibilidades semióticas para uso em benefício do programa. Como afirma Béatrice, "Blache é uma abstração [...] é um ponto e não uma superfície os espectadores não serão tolos qual nada Vicente quer nos fazer crer que este cara existe? Ele o fabricou em estúdio/ Delile [...] a gente adere é verdade". Concernente aos pensamentos suicidas, tudo se torna cômico na enumeração apressada da Sra Delile às jornalistas, num esforço para vender o trágico do casal: "Ele entrava em detalhes técnicos ía fazer isto ou aquilo por uma corda no pescoço ou na viga do sótão ou prender uma pedra ao pescoço ou por fogo na casa cada vez pensando em tudo o fogo na casa era o que lhe vinha com mais freqüência precisava dizer-lhe se eu queria ou não reflita Rose eu não te obrigo".

A própria instituição do trabalho apresenta-se sob o signo do simulacro: "é muito bonito", se diz Delile, desconfiando de sua sorte; tratava-se antes de "uma ocupação fajuta inventada para a circunstância", fruto de uma tramóia entre seu patrão e a televisão. Esse imaginário do complô e do golpe montado remete à falta de confiança em face de um real que já não convence mais. De outro lado, a máquina judiciária, na pessoa do juiz Phélipeaux, reinventa o vivido a partir da manipulação dos indícios colhidos dos testemunhos da viúva Blache e de Delile, como também dos rumores levados por Jacky -a jornalista arrivista- para incriminar Delile sem provas. Esse juiz revela-se, porém, bem consciente da fragilidade de sua própria montagem: "Sabe, no deserto as miragens/ Vai-se vêse crê-se e depois nada/ A areia" (p. 71). O procedimento jurídico de assinatura de um texto de confissão pelo acusado, a despeito da falta de provas e de álibis, é válido para a condenação de alguém, conforme explica Phélypeaux, considerando-se ele próprio como sendo parte de uma engrenagem que anda por si só: "Mas a decisão ele não a tomou ela foi tomada por ela mesma como uma flor que se abre/ O pensamento apaga-se diante de alguma coisa que é de uma outra ordem/Vem o momento em que as hipóteses disparam os dados valsam os fatos partem em todas as direções/ depois/ Mais nada se move/ Nada é jogado e tudo é jogado" (p. 89).

As fronteiras entre as diferentes instituições não são nítidas devido a todas as alianças e contratos obscuros entre elas - $\mathrm{O}$ que reforça a porosidade do real tornado miragem. Essa confusão de territórios faz com que a expressão "passer para o outro lado da tela" perca todo o seu sentido, em razão da circularidade entre o real vivido e o real visto na tevê. O cúmulo da alienação advém do fato de que os desempregados são atores e dramaturgos da encenação televisiva de uma realidade que paradoxalmente vem negar ou mascarar a existência do próprio desemprego. Esse estado de indiferenciação generalizada que dissolve o real à força de um excesso sistemático de manipulação, reduzindo-o ao caos, se reveste curiosamente de um aspecto viscoso, como atestam o termo "magouille" (tramóia) e uma referência à imagem do tubo catódico dos aparelhos de tevê da época. O termo "magouille" era corrente na França ao fim dos anos 1980 e inícios dos anos 1990 - data da peça- e resultava, por contração, de "mare de grenouilles" (pântano de rãs), para significar "os procedimentos tramados no segredo da lama por personagens viscosos" (D'Almeida, 2005, p. 80). 
Quanto à outra imagem, encontra-se numa pintura do jovem Paul, e retrata um pesadelo premonitório deste sobre o destino de Blache e de Delile: "Lembranças dos dois amigos que caem nos braços um do outro e que se fundem um no outro depois de se terem perdido de vista [...] um cilindro cheio de uma espuma viscosa se esparrama por tudo não se vê mais vestígio nem de um nem do outro". Parece-nos claro que se trata de uma referência ao tubo catódico dos aparelhos de tevê que produzia imagem por meio de uma película viscosa em seu interior antes de reenviá-las à tela - uma tecnologia ultrapassada a partir dos anos 2000.

\section{Conclusão}

Por que é tão difícil depreender a mentira nesse texto de Vinaver? Como discernir o verdadeiro do falso e atribuir aos personagens e situações qualificativos nítidos como "bom" ou "mau", "culpado" ou "inocente"? Por que uma jornalista de tevê afirma que a verdade da tevê se encontra no dégradé entre dois pólos?

Ora, o código vinaveriano, como apresentado aqui, evita o maniqueísmo e rejeita a hegemonia de um sentido privilegiado ou oculto sob a superfície do que é dito; o autor desencoraja a busca da profundidade psicológica ou outra, como também o encadeamento de causas e seus efeitos e prega o trabalho com "migalhas de sentido", ao "rés da linguagem", assim como a validade de todos os pontos de vista. Esse "teatro da palavra", "teatro da fala" evita centrar-se em tema ou mensagem privilegiada, para fazer raiar uma multiplicidade de sentidos a partir dos entrechoques inesperados dos "objetos de fala" (palavras, frases, réplicas) que pretendem fazer jorrar centelhas de ironia. Por outro lado, o termo "molecular" constitui outra chave no código de Vinaver. É no plano do mais pequeno que o autor escolhe construir seus textos e propor até mesmo um método de análise textual: "a leitura ralentada de um fragmento basta para revelar essencialmente o modo de funcionamento da obra inteira"; como na geologia ou na biologia, opera-se "por amostragens observadas no microscópio"(Vinaver, 1993, p. 11). E esse modo de "funcionamento dramatúrgico se revela por uma exploração da superfície da fala"; "Que não se procure nada por trás das superfícies, são elas que são o segredo (Goethe)" (Vinaver, 2005, p. 11).

Tal como os personagens Srta Belot ou Paul, com seus sonhos e pinturas, respectivamente, o autor trabalha, em O programa de Televisão, com índices, sintomas, signos esparsos do real, menos para submetê-los a uma verdade única que para compor pedaços de paisagens ricas de sugestões e ambigüidades. Mas se trata ainda do real? As "migalhas de sentido" vinaverianas não seriam, nessa peça de 1990, da mesma categoria dos "restos" postulados por Baudrillard? Posto que, de fato, à força de tantas manipulações pelo sistema, o real já estaria desrealizado, teria já perdido sua consistência, sua espontaneidade, sua seiva vital, sua capacidade de surpreender, e se veria substituído então por uma outra coisa, por um "hiper-real", como quer Baudrillard. ${ }^{4}$

Ora, este real é da ordem do puro signo, da imagem auto-suficiente, desprovida de toda referencialidade externa a ela, ou seja, não é mais nem uma imitação, nem uma representação do real, mas se confunde com o próprio real, ou melhor, ele ocupa o lugar do próprio real enquanto seu simulacro, tornando derrisórias e obsoletas as categorias do falso e do verdadeiro. Enquanto "restos", as "migalhas de sentido" vinaverianas parecem, em O Programa de Televisão, ter a função de resgatar o real desaparecido e, desse modo, testemunhar o esforço do autor para forjar um real em seu teatro, utilizando-se dos mesmos procedimentos do sistema que ele deseja desmon-

\footnotetext{
4 Michel Vinaver, em carta a Catarina Sant'Anna, datada de Paris, 18/02/2008, julga frutuoso "o ângulo de ataque" da metis, e nosso artigo "um estudo denso e esclarecedor", "um belo exemplo de pesquisa no domínio do teatro", mas discute a aproximação entre suas "migalhas de sentido" e os "restos" de Jean Baudrillard. Para Vinaver: "Bem sumariamente, eu diria que Paul e Jacky ganham o real amando-se, que Rose e Delile não o perdem complemente malgrado sua submissão, que há resquícios dele em Béatrice, que ele fica inteiro na sonhadora Bellot; e que em revanche os Blache, Adèle, Phéyipeaux estão no simulacro". (citação autorizada em entrevista à autora, em 03/09/2010, em Paris)
} 
tar. Estaria aí o grande jogo desse teatro, desfazer o jogo do sistema com as armas do próprio sistema? Um pouco como se o autor agisse como aprendiz de feiticeiro, dotado de uma "inteligência astuciosa" (metis) ao lançar armadilhas contra o próprio meio de onde elas provieram. Uma vez que o efeito de real construído de migalhas de real quotidiano por Vinaver não visaria absolutamente à conservação da ordem estabelecida, mas, muito pelo contrário, visaria a inquietar e a incomodar o público, já que o autor não crê que o teatro possa constituir um instrumento revolucionário de fato, justamente pela situação privilegiada do público que freqüenta os teatros.

Parece-nos, então, que O Programa de Televisão deva ser considerado canônico da dramaturgia do autor, por seu mecanismo de construção e fundo iconoclasta. Mas para levar até o fim esta ordem de questionamentos tecidos aqui, poder-se-ía interrogar finalmente sobre os reais efeitos pretensamente incômodos desse teatro, uma vez que, como afirma Baudrillard, o sistema tem necessidade desses tipos de denúncias justamente para poder reforçar ainda mais o efeito de real fabricado por ele, ou seja, para nos fazer crer que existe ainda real sob o oco da imagem fabricada do hiper-real. De todo modo, fazendo-nos visitar esses "porões aonde ninguém jamais desce" (para citar aqui as palavras do jovem marginal e "dissidente" Paul), esse teatro cumpriria ao menos a missão de nos tirar toda pretensão de inocência. 


\section{REFERÊNCIAS}

BAUDRILLARD, Jean: Simulacres et simulation. Paris, Éditions Galilée, 1981.

COLOMBO, Furio: Televisión: la realidad como espetáculo. Versión castellana de Esteve Riambau i Saurí. Barcelona, Gustavo Gili, 1976.

D’ALMEIDA, Fabrice: La manipulation. Paris, PUF, 2005.

DETIENNE, Marcel et VERNANT, Jean-Pierre: Les ruses de l'intelligence- la mètis des grecs. Paris, Flammarion, 1974 [2004].

ROBRIEUX, Jean-Jacques: Rhétorique et argumentation, 2ème éd. revue et augmentée Paris, Armand Colin, 2000.

SANT'ANNA, Catarina: Para desmontar o sistema: a atualidade no teatro de Michel Vinaver, in Ouvirouver (N. 5, 54-60), Uberlândia-MG, UFU, 2009.

SANT'ANNA, Catarina. Teatro e "história imediata": o caso de Os Ajudantes de ordens (Les Huissiers), de Michel Vinaver. In: PARANHOS, Kátia R. (org.) História, teatro e politica. São Paulo: Boitempo, 2012. p. 221-244

SANT'ANNA, Catarina. Teatro e história em Michel Vinaver: as estratégias poéticohistoriográfica de Ephigénie Hôtel (1959). Disponível em: http://www.encontro2012. sp.anpuh.org/site/anaiscomplementares

VINAVER, Michel. L'Émission de télévision. Arles, Actes Sud-Papiers, 1990.

VINAVER, Michel. Dissidente. O Programa de Televisão. Tradução, apresentação e notas de Catarina Sant'Anna. São Paulo, EDUSP. 2007.

VINAVER, Michel (dir.). Écritures Dramatiques - essais d'analyse de textes de théâtre. Arles, Actes Sud, 1993 